\title{
The Accelerator as an Organizational Form: A Review and Reconceptualization
}

\section{Other Conference Item}

\section{Author(s):}

Vandeweghe, Laurens; Sharapov, Dmitry; Clarysse, Bart

Publication date:

2019-08-01

Permanent link:

https://doi.org/10.3929/ethz-b-000379494

\section{Rights / license:}

In Copyright - Non-Commercial Use Permitted

Originally published in:

Academy of Management Proceedings 2019(1), https://doi.org/10.5465/AMBPP.2019.12167abstract 


\title{
THE ACCELERATOR AS AN ORGANIZATIONAL FORM: A REVIEW AND RECONCEPTUALIZATION
}

\begin{abstract}
While the widespread phenomenon of the business or seed accelerator has enjoyed increasing attention amongst scholars, the lack of a coherent and theoretically grounded understanding of this organizational form constrains the cumulativeness and transferability of findings. By drawing on a systematic literature review, we identify four distinct research orientations on the accelerator: organizational learning and adaptation, entrepreneurial finance, entrepreneurial ecosystems, and corporate innovation and entrepreneurship. We compare and contrast these orientations along the organizational features that they attribute to the accelerator and synthesize them into an integrative typology. We further distinguish the accelerator from other established organizational forms in the entrepreneurial support landscape and develop a research agenda that contributes to integration of the literature by building bridges between the different research orientations and linking the concept to established theories.
\end{abstract}

\section{Keywords:}

Business accelerator; organizational form; literature review; typology 


\section{INTRODUCTION}

Since Y Combinator was established as the first accelerator in 2005 and some of its early graduates gained rapid success (e.g. Reddit, Airbnb, Dropbox, Stripe, etc.), this form of entrepreneurial support organization has spread worldwide (Younger \& Fisher, 2018). In 2016, there were more than 500 active accelerators making investments exceeding $\$ 200 \mathrm{M}$ in 11,305 startups globally ${ }^{1}$. While the first accelerators aimed to provide angel investors and venture capitalists (VCs) with a deal-flow of startups (Stayton \& Mangematin, 2018), recent years have seen the birth of different models, such as corporate accelerators matching corporations or their customers with startups, and government-driven or university-backed accelerators promoting startups and economic development (Pauwels, Clarysse, Wright, \& Van Hove, 2016; Yang, Kher, \& Lyons, 2018). Following the proliferation of organizations using the label of this "emerging but increasingly prevalent organizational form" (Cohen, Bingham, Hallen, 2018: 38), scholars from different research streams have shown an increasing interest in the accelerator, a "generic organizational form that aims to stimulate entrepreneurship" (Drori \& Wright, 2018: 2; Younger \& Fisher, 2018). Analysis of the ISI Web of Science Citation Index identified more than 100 business, business finance and management papers using the term accelerator in their title, abstract, or keywords ${ }^{2}$, of which half has appeared since 2017.

As often happens with emerging organizational forms that draw increasing academic interest, elaboration of the concept of the accelerator is incoherent. Research on the accelerator concept has largely focused on its program package - intensive programs of limited duration, involving events and intensive mentoring, to cohorts of entrepreneurs or entrepreneurial teams that periodically graduate (e.g., Pauwels et al., 2016) - and how this offering differs from those provided by incubators and angel investors (Cohen, 2013; Cohen \& Hochberg, 2014; Bliemel

\footnotetext{
${ }^{1}$ See http://gust.com/accelerator_reports/2016/global/. By 2018, more than 1,000 entities self-identify as accelerators according to http://www.f6s.com/accelerators.

${ }^{2}$ After manual verification of the use of the term as organizational form to stimulate entrepreneurship.
} 
$\&$ Flores, 2015). Not surprisingly, this narrow conceptualization of the accelerator does not seem to fully capture the organizational form, as several studies have mentioned that the accelerator's organizational features go beyond its program package (e.g., Bliemel \& Flores, 2015; Pandey, Saurabh, \& Pandey, 2017; Richter, Jackson, \& Schildhauer, 2018). However, current research has reported differing interpretations regarding the accelerator's more fundamental organizational features, describing the organization, amongst others, as an “organizational sponsor" (Cohen et al., 2018), a "financial intermediary" (Kim \& Wagman, 2017), an "innovation intermediary" (Gabrielsson, Politis, Persson, \& Kronholm, 2018), a "physical space intermediary" (Clayton, Feldman, \& Lowe, 2018), and an "ecosystem intermediary" or "institutional intermediary" (Goswami, Mitchell, \& Bhagavatula, 2018). Hence, existing studies have only shed partial light on the accelerator as an organizational form by focusing on a specific aspect or empirical variety of the phenomenon, leading to confusion amongst practitioners and scholars alike (Bliemel \& Flores, 2015; Drover, Busenitz, Matusik, Townsend, Anglin, \& Dushnitsky, 2017; Hathaway, 2017).

Insufficient understanding of the organizational form of the accelerator and the different interpretations of each research stream may hamper cumulativeness and transferability of the findings emerging from the growing body of empirical research using this context and constrain its potential to contribute to debates in business and management. Despite its great potential to inform scholars within business and management on a range of different theories and phenomena at multiple levels of analysis (for an overview, see O’Mahony \& Karp, 2017), the lack of conceptual development of the accelerator has made it hard to connect findings within this context to popular research streams. This can explain why research on accelerators seems to be under-represented in the top journals in the fields of business and management ${ }^{3}$.

\footnotetext{
${ }^{3}$ Based on the journals of distinction of the 2018 edition of the Academic Journal Guide of the Chartered Association of Business Schools (CABS).
} 
By drawing on a systematic literature review (Tranfield, Denyer, \& Smart, 2003), the objective of this paper is to build a solid understanding of the accelerator as an organizational form by presenting a synthetic framework of both the shared conceptual features across different research orientations and their divergent premises. Three distinct contributions are offered in this paper. First, we uncover four distinct research orientations that have expressed interest in the existence and emergence of the accelerator and summarize the literature using this categorization: organizational learning and adaptation, entrepreneurial finance, entrepreneurial ecosystems, and corporate innovation and entrepreneurship. Second, we draw on studies on organizational forms (e.g., Carroll, 1984; Romanelli, 1991; Polos, Hannan, \& Carroll, 2002; Hsu \& Hannan, 2005) to identify and elaborate on four themes that constitute the core features of the accelerator and suggest a novel typology which synthesizes the different research orientations and captures their similarities and divergences regarding these features. Third, we provide an agenda for future research grounded in theory and deduced from the novel typology, going beyond previous studies that have called for more attention to the accelerator in general (e.g., Mian, Lamine, \& Fayolle, 2016; Stayton \& Mangematin, 2018; Clayton et al., 2018).

\section{METHODOLOGY}

The research goal led us to adopt a meta-synthesis approach (Hoon, 2013). This approach takes mostly qualitative studies that are often not narrowly focused on a well-defined concept (Thomas \& Harden, 2008; Barnett-Page \& Thomas, 2009) to reach "understanding or interpretive explanations of the phenomenon", rather than predictive theory (Jensen \& Allen, 1996: 554). Consequently, meta-synthesis is particularly useful when studies display disparate findings about the same phenomenon and do not contribute significantly to the full understanding of the phenomenon of interest when considered individually (Rousseau, Manning, \& Denyer, 2008). By accumulating and synthesizing knowledge from a broader set of studies that focuses on the same phenomenon in similar settings, it enables the integration 
or comparison of findings from studies while taking into account important similarities and differences between them (Tranfield et al., 2003). Similar approaches have been used in reviews on other management phenomena that suffered from conceptual confusion such as platforms (Thomas, Autio, \& Gann, 2014) or poorly theorized organizational forms such as state-owned enterprises (Bruton, Peng, Ahlstrom, Stan, \& Xu, 2015).

The interpretative synthesis was done following a three-staged method adapted from Tranfield et al. (2003): (1) identification of studies, (2) evaluation and selection of studies, (3) data extraction and research synthesis. The whole meta-synthesis process was prepared and documented in a research protocol. Prior to locating relevant research, the authors conducted a scoping study and defined the accelerator as an organizational type that offers mentorship programs of limited duration to (teams of) entrepreneurs to stimulate entrepreneurship. A broad definition was chosen as several scholars have raised concerns about the narrow serviceoriented definition of the accelerator currently used in existing research (Bliemel \& Flores, 2015; Pandey et al., 2017; Richter et al., 2018).

\section{Identification of studies}

The literature that was used in the review stems from an extensive search of the ISI Web of Science database for articles that have the term "accelerator*" or "start*up factor*" in their topic. To ensure that only relevant research papers were reviewed, we confined the scope to journals in the fields of business, business finance and management. The bibliographies of the articles were read to identify and subsequently retrieve other articles on the accelerator, including proceedings, working papers, and think tank reports. This process of retrieving studies was repeated until no more new sources were found. After omitting the duplicates and the studies that were not (partly) devoted to the accelerator concept as defined by the authors, a final sample of 349 studies was identified of which 168 published scholarly papers. 


\section{Evaluation and selection of studies}

The identified research studies were then evaluated and selected based on a priori defined inclusion criteria. First, the data set was compared with the journals listed by the Academic Journal Guide of the Chartered Association of Business Schools (CABS), and papers published in journals with two or more stars were included $(n=34)^{4}$. Second, all remaining studies were evaluated against three inclusion criteria relating to the research rigor, based on Glaser and Strauss (1967) and Rheinhardt, Kreiner, Gioia, and Corley (2017). These criteria included: data volume and depth - does the study use a large volume of reliable data from different sources about the issues been explored or compared to enable triangulation and saturation? plausibility - does the study reveal an appropriate level of detail/description to ensure plausibility to the audience? - and transparency - does the study contain a sufficient amount of information describing research design, data collection and analysis procedures to adequately support the researcher's conclusions?

A final sample of 47 research studies was included in the review (see Table 1). The selected studies consist of published scholarly articles (41), conference proceedings (2), think tank reports (2) and unpublished scholarly articles (2). Relying on published as well as unpublished literature, we limit the potential for publication bias (Kepes, Banks, McDaniel, \& Whetzel, 2012).

Insert Table 1 about here

\footnotetext{
${ }^{4}$ The Academic Journal Guide provides a guide to the range, subject matter, and relative quality of the journals in which business and management academics publish (CABS, 2018). For two star journals, the Academic Journal Quality Guide mentions: "Journals in this category publish original research of an acceptable standard. For these well regarded journals in their field, papers are fully refereed according to accepted standards and conventions. Citation impact factors are somewhat more modest in certain cases. Many excellent practitioner oriented articles are published in 2-rated journals" (CABS, 2018: 10)
} 


\section{Data extraction and research synthesis}

To extract data and synthesize the research, a thematic analysis of the research papers was conducted, categorizing the content of text and identifying relationships among the categories (Boyatzis, 1998). The first author constructed a data extraction form, a cross-table which contained relevant information on each study in the sample. Besides factual information such as the study's theoretical base, research question, and unit of analysis, this table also included interpretive information with regards to the accelerator such as the descriptions and (explicit and implicit) assumptions of the author(s) with regards to the accelerator's role, activities, or impact. Rather than focusing on the studies' specific archetypes or empirical contexts, the analysis focused on the generic conceptual underpinnings of the accelerator and the theoretical contexts in which the term is used. Based on this, we identified four distinctive classes of studies across the sample. Consensus between the authors was reached on this classification after multiple iterations of immersion in the literature and mutual discussions.

The classifications formed the basis for the interpretative meta-synthesis. Using themes induced from the thematic analysis and inspired by studies on organizational forms (Carroll, 1984; Romanelli, 1991; Polos et al., 2002; Hsu \& Hannan, 2005), the first author coded the conceptual foundations across these different research orientations. Each cluster and all the studies it contained were coded according to four themes: (1) program package, (2) structure, (3) function, and (4) purpose. Although the definition of organizational form is somewhat contested (McKendrick \& Carroll, 2001; Romanelli, 1991), the chosen themes and the interpretative angle align what these studies consider to be important for characterizing an organizational form. While, traditionally, the common features were seen as a defining element of form (Carroll, 1984), such as "the internal structure and process of an organization and the inter-relation of its subunits which contribute to the unity of the whole organization and to the maintenance of its characteristic activities, function or nature" (McKelvey, 1982: 458), 
scholars have recently extended these ideas to include the role of organizational identity or identity codes as perceived by relevant audiences (Romanelli, 1991; Hsu \& Hannan, 2005; Polos et al., 2002). In this meta-synthesis, we incorporate both the accelerator's objective features as well as audiences' perceptions of the accelerator's unique identity into our analysis.

During the coding process, we recognized that the research orientations' conceptualizations of the accelerator are very similar with regards to the accelerator's program package and structure, but divergent regarding its function and purpose. By continuously comparing and contrasting the studies in the sample focusing on their similarities and divergences, we developed a novel typology that outlines and explicates the four views on the accelerator. In line with Doty and Glick's (1994) recommendation for building theoretical insights through the development of a typology, we carved out ideal types which each represent a unique combination of the organizational attributes that are associated with the relevant outcome, in this case the organizational form of the accelerator.

Below, we first detail the four orientations on the accelerator that we distinguished from the literature. Subsequently, we compare and contrast them according to the two convergent themes - program package and structure - and two divergent themes - function and purpose. On this basis, we then synthesize the four orientations into a novel typological framework.

\section{RESEARCH ORIENTATIONS ON THE ACCELERATOR}

From the dispersed state of literature on accelerators, four main research orientations have been identified, each attributing different roles to the accelerator, focussing on different audiences, and if any, adopting different theoretical lenses (see Table 2 for a summary). In what follows, we review the literature along these four distinct research orientations.

Insert Table 2 about here 


\section{Organizational learning and adaptation}

We refer to the first research orientation as organizational learning and adaptation. The studies within this orientation have conceptualized the accelerator as an "organizational sponsor" (Hallen, Bingham, \& Cohen, 2016; O’Mahony \& Karp, 2017; Cohen et al., 2018) or a "new generation incubation model" (Pauwels et al., 2016; Malek, Miane, \& McCarthy, 2014) that provides resources intended to increase firm survival and success, as part of the broader type of incubation entities or programs (Grimaldi \& Grandi, 2005) but distinct from traditional incubators (Cohen, 2013; Bliemel \& Flores, 2015; Pauwels et al., 2016). Drawing from the literatures on organizational learning and adaptation (Chakravarthy, 1982; Fiol \& Lyles, 1985) and business models (Chesbrough \& Rosenbloom, 2002; Zott, Amit, \& Massa, 2011), the organizational learning and adaptation orientation has focused on understanding (different) accelerators' services and practices (Cohen \& Hochberg, 2014; Adomdza, 2015; Malek et al., 2015; Pauwels et al., 2016; Battistella, De Toni, \& Pessot, 2017; Pandey et al., 2018, Yin \& Luo, 2018; Kreusel, Roth, \& Brem, 2018), whether accelerators affect venture success through organizational learning (Hallen et al., 2016) and which design choices with regards to its services optimize and accelerate learning at the venture-level (Gonzalez-Uribe \& Leatherbee, 2017; Cohen et al., 2018; Stayton \& Mangematin, 2018). To a lesser extent, this orientation has looked at how accelerators get formed by borrowing and deviating from "exemplar forms", such as the Techstars and Y Combinator accelerators (Younger \& Fisher, 2018).

\section{Entrepreneurial finance}

Entrepreneurial finance is a second group of studies that has shown an interest in the accelerator. They conceptualize the accelerator as a "financial intermediary" (Ewens, Nanda, \& Rhodes-Kropf, 2018), "financial organization" (Yu, 2016) or "small VC-fund" (Bernthal, 2017), as part of the entrepreneurial finance landscape, alongside other sources like VC, corporate venture capital (CVC), angel investment and crowdfunding (Drover et al., 2017). 
Assuming that the investment in and valuation of new firms is prone to information assymetries (Sanders \& Boivie, 2004), studies within this research orientation focus on the certification role of accelerators using signaling theory (e.g., Spence, 1973; Connelly, Certo, Ireland, \& Reutzel, 2011), which suggests that startups affiliate with and convey the endorsements of reliable third parties such as accelerators to reduce their uncertainty in the eyes of investors (Kim \& Wagman, 2014; Yu, 2016; Plummer, Allison, \& Connelly, 2015). Entrepreneurial finance studies focus on for-profit investment accelerators, exploring questions related to the governance of these accelerators (Kim \& Wagman, 2014; Bernthal, 2016, 2017), the investment efficiency of accelerator-investments as opposed to direct investments in new ventures (Yu, 2016), or the reasons for and consequences of the emergence of this new form of entrepreneurial financing (Bruton, Khavul, Siegel, \& Wright, 2015; Ewens et al., 2018).

\section{Entrepreneurial ecosystems}

The entrepreneurial ecosystems orientation has conceptualized the accelerator as an “innovation intermediary" (Gabrielsson et al., 2018; Clayton et al., 2018) or "institutional intermediary" operating as a "bridge between the startup and the broader entrepreneurial environmental resources" (Goswami et al., 2018: 117). The studies within this research orientation focus on the macro- and meso-level roles of accelerators, building on the literatures of regional innovation systems (Cooke, Uranga, \& Etxebarria, 1997) and entrepreneurial ecosystems (Acs, Autio, \& Szerb, 2014). They explore the processes that these intermediaries undertake to link entrepreneurs with entrepreneurial environmental resources (Goswami et al., 2018), the impact that they have on the regional entrepreneurial ecosystems in which they are established (Fehder and Hochberg, 2014; Goswami et al., 2018), and the role of (different types of) accelerators in the venture creation pipeline of the regional entrepreneurial ecosystem (Yang et al., 2018), the entrepreneurship education landscape for students (Wright, Siegel, \& 
Mustar, 2017), or the network of innovation-supporting intermediaries of a science commercialization ecosystem (Clayton et al., 2018).

\section{Corporate innovation and entrepreneurship}

A fourth and last research orientation on the accelerator stems from the literature on corporate innovation and entrepreneurship. The studies in this research orientation have looked at corporately-backed accelerators as "organizational devices" (Richter et al., 2018: 69) that act as "interfaces between corporations and startups" (Kohler, 2016: 347) to facilitate "corporate start-up engagement" (Weiblen \& Chesbrough, 2015: 85). They argue that corporate accelerators are involved in "corporate nurturing", a form of corporate entrepreneurship that involves business assistance to new ventures (Miles \& Covin, 2002; Shankhar \& Shepherd, 2018), and have so far looked at the design of corporate accelerator programs (Kohler, 2016; Kanbach \& Stubner, 2016; Richter et al., 2018) and how these programs differ from other startup-engagement activities such as corporate incubation and corporate venturing (Kohler, 2016). Furthermore, corporate innovation and entrepreneurship studies have explored the different models of corporate accelerators (Kanbach \& Stubner, 2016; Shankhar \& Shepherd, 2018; Prexl, Hubert, Beck, Heiden, \& Prügl, 2018) and their success factors and inhibitors for tapping into the startup world (Jackson \& Richter, 2017; Mahmoud-Jouini, Duvert, \& Esquirol, 2018). Overall, this research orientation has focused on the benefits of corporate accelerators for its corporate sponsor(s), building on the literatures on corporate entrepreneurship (Burgelman, 1983), open innovation (Chesbrough, 2003), and business or innovation ecosystems (Moore, 1996; Adner \& Kapoor, 2010).

\footnotetext{
${ }^{5}$ Although studies within corporate innovation and entrepreneurship argue that (corporate) accelerators may not be set up as separately incorporated entities (Prexl et al., 2018), we will consider the internal corporate accelerator as a type of the organizational form of the accelerator. Much alike "internal corporate incubators" (Gassmann \& Becker, 2006) or "micro new ventures departments" (Burgelman, 1983; Burgelman, 1984), they consist of teams of different individuals of various functional groups that interact, make decisions and take actions to nurture new businesses (as an entity) (Burgelman, 1983; Shankhar \& Shepherd, 2018).
} 


\section{SHARED AND DIVERGENT FEATURES OF THE ACCELERATOR}

The four research orientations outlined above display some similarities and differences regarding their conceptualization of the accelerator. As existing literature has not considered these similarities and differences, it has arguably limited our holistic understanding of the accelerator. By taking all these studies together, a more cohesive and interpretative view on the accelerator can be seen. While the four research orientations show similarities regarding their view on the accelerator's program package and structure, they diverge regarding their perspective on the function and purpose of the accelerator.

\section{Shared features of the accelerator}

The four research orientations on the accelerator converge regarding their characterizations of the accelerator's program package and structure.

\section{Program package: a time-limited, cohort-based mentorship and networking program for} entrepreneurs. The four research orientations argue that the accelerator program is typically time-limited and cohort-based, involving mentorship and networking, and offered to entrepreneurs or entrepreneurial teams that will often get selected through an open and competitive application process (Miller and Bound, 2011, Pauwels et al., 2016). The time limited duration of the program - mostly between 3 and 6 months - and the cohort-based intake - referring to the simultaneous admission of a new group of entrepreneurial teams - are often put forward as the most defining features of the accelerator (Cohen, 2013; Bliemel \& Flores, 2015). Mentorship - advice and help from (former) entrepreneurs, potential corporate clients or (former) investors - is also considered key to the accelerator program (Bernthal, 2016, 2017). Optional features of the accelerator program relate to the seed-investment (e.g. Pauwels et al., 2016; Bernthal, 2016; Cohen, 2013; Cohen \& Hochberg, 2014; Hochberg, 2015), the availability of office space, and the pitch event upon graduation or "demo day", where entrepreneurial teams get the opportunity to pitch their business in front of potential investors 
and/or customers (Miller \& Bound, 2011; Cohen, 2013; Cohen \& Hochberg, 2014; Hochberg, 2015). Another optional feature concerns some form of standardization of the program across the different ventures, such as the investment terms (Kim \& Wagman, 2014), the screening process (Pauwels et al., 2015) or the learning and interaction activities of the program (Cohen et al., 2018; Bernthal, 2016; Ewens et al., 2018). This standardization has arguably allowed some accelerators to rapidly expand the amount of startups they take on board for each cohort (Kohler, 2016) and replicate their model across different sectors and regions (Malek et al., 2014). For example, while Y Combinator's first batch in the summer of 2005 consisted of 8 startups, the accelerator accepted more than 100 participants in its 2016-batch ${ }^{6}$. Similarly, Techstars launched their privately-funded program in Boulder in 2007 and scaled up to 43 (corporate- and privately funded) programs worldwide in 2018 that have guided more than 1500 companies $^{7}$.

Structure: an organic structure that allows fast decision-making and enables informal interaction. An organization's structure is defined as "the sum total of ways in which it divides its labor into distinct tasks and then achieves coordination among them" (Mintzberg, 1979: 2), or a system of practices for organizing activities (Burns \& Stalker, 1961). The most prevalent typology for describing the fundamentals and fundamental differences in organizational structure is the organic versus mechanistic organization (Burns \& Stalker, 1961; Ambrose \& Schminke, 2003). Organic organizations are generally characterized by overlapping responsibilities, flexible and unwritten procedures, distributed or decentralized decision making, and consultative or lateral communication, whereas mechanistic organizations are most typically defined in terms of high degrees of specialization and division of labor, fixed

\footnotetext{
${ }^{6}$ https://www.ycombinator.com/

7 http://www.techstars.com/
} 
and written procedures, and a hierarchical and centralized command structure (Burns \& Stalker, 1961; Galbraith, 1977; Hatch, 1997; Donaldson, 2001).

Whereas accelerators display differences in funding (e.g., funded by private, corporate, public or a combination of these sources; through a limited partnership or as part of a permanent organization), and management structures (e.g., investor or sponsor firm taking on the management role or outsourcing management to an accelerator operator), studies across the four research orientations describe the accelerator's "modus operandi" as largely adhering to the organic type of organization. As such, the different research orientations argue that the accelerator represents the emergence of a lightweight governance model (Weiblen \& Chesbrough, 2015; Ewens et al., 2018), involving limited hierarchy and relatively small staffs as the organization's intensive mentorship demand is often met by a volunteer network of experts (Cohen \& Hochberg, 2014; Bernthal, 2016). The accelerator structure allows fast decision making (Weiblen \& Chesbrough, 2015; Richter et al., 2018) and enables informal interactions by generating norms of trust, openness and volunteerism (Bernthal, 2016, 2017; Hallen et al., 2016). Even corporate accelerators that act in-between the often mechanistic structures of the corporate parents and organic structures of entrepreneurial actors (Souitaris, Zerbinati, \& Liu, 2012), have been argued to be structurally similar to other accelerators with an essential common feature being that they are separated from the established organization (Richter et al., 2018: 76) to "create a protected environment from corporate structures for internal and external entrepreneurs" (Kanbach \& Stubner, 2016: 1771).

\section{Divergent features of the accelerator}

While converging on the two above features, the four research orientations on the accelerator also diverge regarding their characterizations of the function of the accelerator and their purpose. These two divergences contribute to fragmentation among the four research orientations, and, more generally, to a lack of integration in the literature. 
Function: open-system intermediation vs. closed-system intermediation. Accelerators are often conceptualised as intermediaries that connect new ventures with external sources of knowledge and resources. In general, the concept of intermediation represents a process of linking two or more individuals or organizations within a specific context through knowledge and information (Howells, 2006) to bring about an activity that may not have been possible by direct trading between the parties (Dutt, Hawn, Vidal, Chatterji, McGahan, \& Mitchell, 2016).

In the case of the accelerator, two types of intermediation have been assumed by the different research orientations: open-system intermediation and closed-system intermediation (Dutt et al., 2016; Giudici, Reinmoeller, \& Ravasi, 2018). Open-system intermediation brings about activities that seek to create benefits for parties or a common good beyond a well-identified set of participating actors by improving the capabilities of particular organizations through the facilitation of learning and commercialization of their products or services through community engagement (Dutt et al., 2016; Giudici et al., 2018). In contrast, closed-system intermediation concerns activities primarily focused on improving the performance or private gains of a restricted set of (central) actors in a network by coordinating and harnessing dispersed resources and capabilities to contribute to that network or a given collective innovation output (Dhanaraj \& Parkhe, 2006; Nambisan \& Sawhney, 2011; Dutt et al., 2016; Giudici et al., 2018). While in practice, accelerators may engage in both closed and open-system intermediation to a certain extent ${ }^{8}$, the identified research orientations tend to focus on one or the other.

Two research orientations assume that the accelerator engages mainly in open-system intermediation. Organizational learning and adaptation studies highlight the accelerator's role

\footnotetext{
${ }^{8}$ In line with Dutt et al. (2016: 822) and Giudici et al. (2018: 1370) we build on the argument that "'openness' may be a matter of degree" but deviate from their categorical distinction regarding whether the role intermediaries play is open at all (e.g. if an intermediary engages in some kind of open system intermediation, it is considered an open system intermediary) by highlighting the open vs. closed-system intermediation processes rather than the open- vs. closed-system intermediary.
} 
of initiating links between the participating ventures and the mentors, program directors, potential customers and partners, alumni and peers (Hallen et al., 2016) or, more broadly, offering access to and facilitating knowledge flows with (mainly external) resource providers (Cohen, 2013; Pauwels et al., 2016; Battistella et al., 2017). While some studies have explored the level of disclosure of sensitive information between the participating ventures (e.g., Cohen et al., 2018), this research orientation largely assumes that the interests between the accelerator participants mutually or the participants and the sponsors or mentors are aligned and that the accelerator's benefits are accrued to its participants and the broader environment.

Entrepreneurial ecosystems studies also focus on open-system intermediation. They argue that the accelerator transforms the beliefs and coordinates the actions of individual actors in the entrepreneurial ecosystem in a way that enhances their overall commitment to the entrepreneurial ecosystem (Leatherbee \& Eesley, 2014; Goswami et al., 2018). Some of these studies consider the accelerator itself as a policy instrument to support the commercialization of science and market uptake of innovations (Gabrielsson et al., 2018; Clayton et al., 2018). This research orientation does not mention any tensions or conflicting interests between the participants mutually or the participants and the sponsors or mentors, and departs from the idea that accelerators (private or corporate) contribute to the entrepreneurial infrastructure that supports the development of early stage ideas into later-stage startups (Goswami et al., 2018).

In comparison, studies stemming from entrepreneurial finance and corporate innovation and entrepreneurship assume that the accelerator is largely involved in closed-system intermediation. Entrepreneurial finance studies argue that the accelerator provides investment to accepted ventures in return for equity or a convertible note (Kim \& Wagman, 2014; Yu, 2016). They emphasize the value capture of the accelerator for private investors and assume multiple tensions and conflicting interests within this setting. For instance, Bernthal (2016, 2017) has looked at how the risk of expropriation of the startups by mentors or sponsors can 
be reduced by generating and enforcing norms, thereby highlighting the misappropriation incentives of both parties. Furthermore, according to Kim and Wagman (2012), accelerators that have a vested interest in the ventures that they are certifying, may be incentivized to withhold negative signals about them thereby misleading future investors.

Corporate innovation and entrepreneurship studies also focus on closed-system intermediation and consider the accelerator as an interface unit that matches and mediates between entrepreneurs and corporations ${ }^{9}$. Studies within this research orientation have paid attention to "coopetition" tensions between the ventures and the corporate sponsors (Jackson \& Richter, 2017) and competition battles for strong startups and key corporate resources (MahmoudJouini et al., 2018).

Purpose: venture acceleration vs. system acceleration. The concept of acceleration, an increase in velocity of an object with respect to time, constitutes an important commonality across the different research orientations. Research on time and organizational development has argued that acceleration of a process is caused by self-reinforcing positive feedback cycles, where changes in one variable lead to changes in another variable which lead back to changes in the first variable (Bluedorn, \& Denhardt, 1988; Ancona, Okhuysen, \& Perlow, 2001).

In line with existing research on the pacing of events which has said that this can be internal to an organization or pertaining to its environment (Ancona et al., 2001), we distinguish two main types of acceleration that accelerators aim at: venture acceleration ${ }^{10}$ and system acceleration. Life-cycle studies have argued that entrepreneurial ventures go through distinct phases such as

\footnotetext{
${ }^{9}$ While the concept of open innovation is often used in the studies within this orientation, the meaning of open innovation as a "use of purposive inflows and outflows of knowledge to accelerate internal innovation and expand the markets for external use of innovation" (Chesbrough, 2006: 1) confirms the prevalent closed-system intermediation perspective on the accelerator in that the flows of knowledge between the corporate and the new ventures are primarily meant to create benefits for the corporate sponsor.

${ }^{10}$ Note that venture acceleration also includes the acceleration of "ventures" that have not been incorporated, such as the entrepreneur or entrepreneurial team and their pre-launch resources and conditions.
} 
conception, development, commercialization, growth, etc. (e.g., Kazanjian, 1988). Venture acceleration or speeding up the events in the evolution of entrepreneurial ventures is considered important in the highly competitive and high-velocity business environments in which many of them compete (Brown \& Eisenhardt, 1997). We refer to system acceleration as the pacing of events pertaining to the external environment of the accelerator. This external environment could be the entrepreneurial ecosystem (Acs et al., 2014), innovation system (Cooke et al., 1997), innovation ecosystem (Adner \& Kapoor, 2010), or corporate system (Bloodgood, Hornsby, Burkemper, \& Sarooghi, 2015). The latter refers to the dynamic and complex system of relationships that exists among a corporation's internal corporate entrepreneurship activities to stimulate corporate innovation and entrepreneurship within the boundaries of the firm (Bloodgood et al., 2015). While, in practice, accelerators may embody both purposes to a certain extent, each research orientation tends to emphasize on either venture or system acceleration.

Two research orientations focus on the venture acceleration purpose of the accelerator. Organizational learning and adaptation studies primarily argue that the accelerator aims to accelerate the development of the capabilities of the entrepreneurial teams (Hallen et al., 2016), or the set of skills and resources needed to start and grow their nascent businesses such as know-how, reputation and social networks (Gonzalez Uribe \& Leatherbee, 2017). These studies further argue that the accelerator enables rapid testing and adaptation of venture ideas to become scalable and market-proof or to fail quickly, leading to quicker venture growth or failure (Cohen, 2013; Cohen \& Hochberg, 2014; Cohen et al., 2018).

Similarly, studies from the entrepreneurial finance orientation have also focused on the accelerator's purpose of speeding up venture development towards either success or failure. They argue that the accelerator does so by providing investment to new ventures (Yu, 2016), connecting these new ventures to follow-on investors during and after the program (Bruton et 
al., 2015), and exerting a certification effect by reducing the information asymmetries between the new ventures and follow-on investors (Kim \& Wagman, 2012; Plummer et al., 2016).

Studies stemming from the research orientation of entrepreneurial ecosystems have mostly considered the accelerator's system acceleration purpose. They argue that the accelerator aims to speed up the commercialization of science at the system level (Clayton et al., 2018), attract VC funding to the local region (Fehder \& Hochberg, 2014), grow a regional network of graduates and mentors, and stimulate more entrepreneurship-focused government policies (Goswami et al., 2018). Some of these studies have also linked venture development acceleration to system acceleration by arguing that speeding up the cycle of the venture leading to quicker growth or quicker failure ${ }^{11}$ - and creating ecosystem commitment amongst the participating ventures accelerates the development of the ecosystem (Goswami et al., 2018).

Studies stemming from the research orientation of corporate innovation and entrepreneurship also focus on the system acceleration purpose of the accelerator to speed up the development of a corporate system or innovation ecosystem. With regards to the (internal) corporate system, this research orientation has considered the accelerator as a mechanism for large corporates to stimulate and potentially insource external innovation (Weiblen \& Chesbrough, 2015; Kanbach \& Stubner, 2016; Shankhar \& Shepherd, 2018), rejuvenate corporate culture (Kohler, 2016; Kanbach \& Stubner, 2016) or find next generation products or threads to existing products (Kanbach \& Stubner, 2016; Richter et al., 2018). Accelerating development of the (external) innovation ecosystem is reached through facilitating partnerships or (complementary)

\footnotetext{
${ }^{11}$ In the case of quicker failure, the ecosystem will benefit if those entrepreneurs move on to higher-value opportunities.
} 
innovation around the corporation's existing business (Weiblen \& Chesbrough, 2015; Sivonen et al., 2015; Kanbach \& Stubner, 2016; Shankhar \& Shepherd, 2018).

\section{A TYPOLOGY OF PERSPECTIVES ON THE ACCELERATOR}

Above, we have compared and contrasted four research orientations on the accelerator and the shared and divergent features that are attributed to the accelerator across these different research orientations. Below, we present a novel typology which emerged from the juxtapositions of the research orientations' divergent views on the accelerator. As captured in Figure 1, all four research orientations share similar views on the accelerator's features of program package and structure but are distinguished by their divergent views on the accelerator's function and purpose.

Insert Figure 1 about here

\section{The accelerator as an organizational sponsor}

The view on the accelerator as an organizational sponsor maps onto the organizational learning and adaptation orientation. Studies within this view acknowledge that accelerators link the new ventures to the environmental context or ecosystem, but focus on whether and how the accelerator impacts the trajectories of the new ventures through an intermediation that is in the interest of the new ventures and the broader entrepreneurial community. Exemplary for this view, studies have likened the accelerator to an organizational sponsor which attempts to foster entrepreneurship and encourage the growth of new ventures "by creating a resource-munificent context intended to increase survival rates among those organizations" (Amezcua, Grimes, Bradley, \& Wiklund, 2013: 1). Other organizational sponsors include incubators, science parks, universities, and government programs (Phan, Siegel, \& Wright, 2005; Rothaermel \& Thursby, 2005; Amezcua et al., 2013; Dutt et al., 2016; Armanios, Eesley, Li, \& Eisenhardt, 2017). 


\section{The accelerator as a financial intermediary}

A second view regards the accelerator as a financial intermediary that connects surplus and deficit agents by transferring funds from one economic agent to another by means of the issuance of a financial security, i.e. an asset for the surplus agent and a liability for the deficit agent (Pilbeam, 2005). This view has so far been adopted by studies within entrepreneurial finance, focusing on venture acceleration through directive intermediation that is primarily in the interest of the sponsors (i.e., mostly the angel investors and institutional investors that typically sponsor investment or equity accelerators). Similar to financial intermediaries such as banks, mutual funds and VCs (Gompers \& Lerner, 2004), the accelerator shares investments' fixed costs (e.g., evaluation, monitoring, and guidance of the new ventures), mitigates asymmetric information by getting and signalling specialised knowledge (e.g., about the new ventures' technologies) and reconciles the often conflicting needs of the surplus and deficit agents (e.g., avoiding misappropriation of knowledge).

\section{The accelerator as an ecosystem intermediary}

A third ideal-typical view regards the accelerator as an ecosystem intermediary, currently employed by studies within the research orientation of entrepreneurial ecosystems. The focus of this view rests on system acceleration through prosocial intermediation that is in the interest of the ventures and the broader entrepreneurial community. The notion of the accelerator as an ecosystem intermediary can be further conceptualized as an institutional intermediary that links different parties to create, develop, change or substitute for institutions (Mair, Marti, \& Ventresca, 2012; Dutt et al., 2016; Eberhardt \& Eesley, 2018), or as an innovation intermediary that supports the collaboration between two or more parties during the innovation process ranging from linking parties for collaboration to mediating relationships and bridging knowledge, competency and capability gaps (Bessant \& Rush, 1995; Howells, 2006; Klerkx \& Leeuwis 2008). 


\section{The accelerator as a startup engagement vehicle}

A last view considers the accelerator as a startup engagement vehicle. This view corresponds with the research orientation of corporate innovation and entrepreneurship and focuses on the accelerator's purpose to accelerate an internal corporate system or external innovation ecosystem through closed-system intermediation which is largely directive and in the interest of one or more of its corporate sponsors. The accelerator as a (corporate) startup engagement vehicle considers the accelerator's activities as a type of corporate nurturing to speed up innovation to the benefit of the corporate system or innovation ecosystem (Shankar \& Shepherd, 2018). The accelerator is then part of externally oriented corporate entrepreneurship vehicles, like CVCs (Narayanan, Yang, \& Zahra, 2009; Phan, Wright, Ucbasaran, \& Tan, 2009), or some corporate incubators (Gassmann \& Becker, 2006). Similar to these corporate entrepreneurship vehicles, the accelerator as a startup engagement vehicle can be operated within the firm, structured through a wholly or partially owned subsidiary or serviced through an accelerator service provider (Prexl et al., 2018).

\section{THE ACCELERATOR AND OTHER ENTREPRENEURIAL SUPPORT ORGANIZATIONS}

In what follows, we will compare the accelerator with other entrepreneurial support organizations that have been said to have a distinct organizational form, such as the incubator (Phan et al., 2005) and the VC (Gompers \& Lerner, 2004). While some studies on accelerators have previously looked at the differences between these institutions and the accelerator based on their program package (i.e., Battistella et al., 2017; Cohen \& Hochberg, 2014; Pauwels et al., 2017; Bliemel et al., 2015), we will discuss their differences based on the broader organizational features of the accelerator as outlined in this paper.

The accelerator differs from the incubator in three major ways. A first difference is well-known in extant literature and relates to the accelerator's program package. Whereas incubators 
generally take on new incubatees on a continuous basis and the incubation period is not limited in time, accelerators typically provide cohort-based, time-limited programs. Second, accelerators and incubators differ in how they execute their intermediation function. While incubators temporarily encourage their incubatees to isolate or "buffer" themselves from the environment to avoid environmental threats (Scillitoe \& Chakrabarti, 2010; Amezcua et al., 2013), accelerators typically speed up external interactions early on, reducing the amount of co-dependency between the participating startups and the sponsors and encouraging firms to confront market selection mechanisms quickly (Cohen et al., 2018). A last difference relates to the concepts of venture and system acceleration. While incubators support the creation and growth of ventures by providing them with incubator space, business support services, and networking opportunities, they are typically dependent on charging rent or membership fees to residents (Aerts, Matthyssens, \& Vandenbempt, 2007) and are hence not incentivised to speed up the development of the ventures. In comparison, accelerators aim at speeding up the process of ventures and select startups which are scalable, investable and show an ability to grow rapidly within months. Consequently, incubators may add to the development of a system such as an entrepreneurial ecosystem, but to a different extent than accelerators.

$\mathrm{VC}$ is another institution in the startup support scene that has been likened to (investment) accelerators. VCs raise funds from a set of limited partners (pension funds, etc.) and seek to provide a return to these investors through selective investments into a portfolio of young, innovative companies (Gompers \& Lerner, 2000). There are three main differences between VCs and accelerators. First, although VCs often work closely with the ventures in which they invest to provide guidance and value beyond capital (Sapienza, 1992), the structure and intent of their guidance is different. Instead of investing in companies on an ad-hoc and ongoing basis like angel investors and venture capitalists, accelerators select cohorts of companies through an application process once or twice during a year. As opposed to a $\mathrm{VC}$, the magnitude and 
frequency of mentorship is much higher in an accelerator. Second, accelerators typically target more early stage ventures with inexperienced teams with a higher risk of failure. An investment accelerator, for example, enables a more passive "spray-and-pray" investment strategy or "passive" seed investments in return for small equity stakes in relatively inexperienced teams involving limited governance (Ewens et al., 2018), instead of more governance involvement and investments in the hundreds of thousands, or even millions that would be expected from VCs. Third, unlike typical VC funds that must be liquidated within a limited time frame, an accelerator vehicle does not have a hard deadline for dissolvement. The investment accelerator affords time flexibility for portfolio companies that do not seek an exit event (Bernthal, 2016).

\section{FUTURE RESEARCH}

Based on a sample of 47 research studies on the accelerator, this paper has synthesized the existing literature, organized the different research orientations into an integrative typological framework, and linked each typology to higher-level concepts like organizational sponsors, financial intermediaries, institutional or innovation intermediaries and startup engagement vehicles. For future research, we present a research agenda that cuts across the different research orientations and focuses on the theoretical debates that research on accelerators could contribute to. First, we will discuss some promising avenues for research that bridges the divergent perspectives on the accelerator. Second, we will present four theories that research on the accelerator across the different research orientations could speak to.

\section{Building bridges between the divergent features of the accelerator}

Linking open and closed-system intermediation. While current research on the accelerator has largely assumed that the accelerator is involved in open-system intermediation in the interest of the startups and the broader community or closed-system intermediation in the interest of the investors or the corporate sponsors, in practice, both open-system and closed-system intermediation will often co-occur or be expected from the accelerator (Dutt et al., 2016). So 
far, it remains unclear how the accelerator can cope with or leverage the conflicts stemming from the (expected) co-occurrence of these two forms of intermediation and combine or portray to combine both. Future research could explore how such hybrid-system intermediaries deal with these differing stakeholder expectations (O’Mahony \& Bechky, 2008), and respond to the apparent paradox through (a combination of) acceptance, synthesis, spatial and temporal separation (Poole \& Van de Ven, 1989; Smith \& Lewis, 2011).

Linking venture and system acceleration. Research on the accelerator tends to focus on venture acceleration or system acceleration and foregoes on the fact that, in many cases, the pace of the venture and the system must be aligned through (mutual) adjustment (Pérez-Nordtvedt, Payne, Short, \& Kedia, 2008). This adds new dynamics to the acceleration process. In aligning the ventures with the system, "entrainment" or "adjusting the pace or cycle of one activity to synchronize with that of another" (Ancona, Goodman, Lawrence, \& Tushman, 2001: 656), is going to be essential. Future research could identify and explore the processes and different types of entrainment in the accelerator context. For example, we believe that entrainment will be particularly important between the ventures and the platform ecosystem in the case of a platform accelerator or between the ventures and the corporate system in the case of a corporate accelerator. Furthermore, insights beyond our current understanding of the acceleration of either the venture or the system could add to the debates on acceleration in innovation and social processes more broadly (Rosa, 2013; Lifshitz-Assaf, Lebovitz, \& Zalmanson, 2018).

\section{Improving theory building using the accelerator}

Four orientations appear to have dominated prior research on the accelerator: organizational learning and adaptation, entrepreneurial finance, entrepreneurial ecosystems and corporate innovation and entrepreneurship. Although some of the studies within these research orientations have drawn from established theories, the majority has remained descriptive and does not sufficiently connect to mainstream theoretical streams in strategy, 
entrepreneurship and management in ways that can enrich our understanding of the accelerator, as well as contribute to the development of these theories. To help remedy these shortcomings, we discuss three theories that research on accelerators could speak to. We chose these theories because of their conceptual closeness to key accelerator research issues. The suggested theories are by no means exhaustive. Rather, they illustrate the rich variety of promising issues to be explored in future research.

Entrepreneurial cognition. We believe that the context of the accelerator provides a fertile ground for research on entrepreneurial cognition - "the people side of entrepreneurship" (Mitchell, Busenitz, Lant, McDougall, Morse, \& Smith, 2002: 93). As accelerators focus on the development of teams' entrepreneurial capacities, they offer a great setting to study entrepreneurial cognitions, "the knowledge structures that people use to make assessments, judgments or decisions involving opportunity evaluation and venture creation and growth" (Mitchell et al., 2002: 97). Scholars and policy makers have voiced the need for a better understanding of the dynamic relationships between mind, environment, and entrepreneurial action and called for research to probe the interactions of different cognitive variables of interest across levels of analysis (Grégoire, Corbett, \& McMullen, 2011). For example, accelerators provide mentoring services to accepted teams as one vehicle through which entrepreneurs and entrepreneurial teams develop, fine-tune their business ideas and gain skills. Future research could explore how this mentoring process influences entrepreneurial learning by exploring, for example, the types of entrepreneurs that are coachable (Bryan, Tilcsik, \& Zhu, 2017) or how entrepreneurs (fail to) transform mentoring advice into their businesses (Grimes, 2017). Furthermore, this research orientation could also investigate whether and how entrepreneurs outside of accelerators benefit from vicarious learning or knowledge spill-overs and how entrepreneurs change the knowledge and belief systems of the entrepreneurial ecosystem. 
Governance theory. Governance theory is about the practice of creating the conditions and rules for collective decision making (Stoker, 1998), and is of relevance in organizations where conflict of interests are present that cannot be dealt with through a contract (Hart, 1995). The accelerator is a lightweight organizational model and will orchestrate different external stakeholders in its intermediation efforts, such as mentors, follow-on investors, serviceproviders, etc. These stakeholder groups may each have differing objectives which will lead to interest conflicts. Given the number of investments, the accelerator could provide an interesting setting to explore whether and how financial intermediaries exert more (or less) control rights over the development of accepted teams when differences in opinions and interests occur. For instance, while extant studies have recognized that accepted entrepreneurs may learn from their cohort members partly because of similarities in resources or knowledge (Cohen et al., 2018), this also involves a risk of leaking information to potential competitive firms. Accelerator's large portfolio of entrepreneurial firms may increase this risk due to "competitive information leakage" via the investor, likely inhibiting innovation (Pahnke et al., 2015). It is of great value to examine whether such information leakage occurs in accelerators and how the positive and negative effects of information disclosure can be managed.

Institutional theory. Research on the accelerator could benefit from the institutional theory. Institutions consist of formal rules (statute law, common law, regulations) and informal constraints (conventions, norms of behavior, and self-imposed codes of conduct) that structure human interaction (North, 1990). While the institutional role of accelerators in overcoming institutional voids has received some attention (Leatherbee \& Eesley, 2014; Goswami et al., 2017), research on the accelerator could contribute more directly to current debates within institutional theory, and more specifically, to institutional theory's "central construct" (Wooten \& Hoffman, 2008) of the institutional field or the set of organizations that interacts together "frequently and fatefully" (Scott, 1995: 207-208). Accelerators that operate within institutional 
fields that are formed around an issue such as an industry transition, societal challenge, or novel economic opportunity, will often involve and intermediate between a diverse set of actors with distinct and sometimes conflicting identities, goals, norms, and practices (Zietsma et al., 2017). Future research on the accelerator using institutional theory could look at how accelerators that operate within an issue field effectively mobilize the different actors and mediate between / align their practices and interests to initiate or change institutional fields. Which tensions do the different involved parties perceive (e.g. venture vs. system acceleration, open vs. closedsystem intermediation) and how does the accelerator as an intermediary cope with these tensions and enable collaboration between the actors (O’Mahony \& Bechky, 2008)?

Organization design theory. At last, research on the accelerator could benefit from organization design theory. Organization design theory has developed around the division of labor within and in-between organizations for a certain task, often an innovation effort, and the coordination of those parts into a meaningful whole (Sanchez \& Mahoney, 1996). Using the context of corporate accelerators, theory on organization design could help to understand whether corporate accelerator vehicles are substitutive or complementary to other internal or external corporate entrepreneurship initiatives (e.g., CVC) in the search for innovation, when and how "outsourcing" innovation to external corporate accelerators contributes to organizational success and how the corporate accelerator operating as a boundary-spanner between the firm and its ecosystem enables innovation at both sides. Furthermore, research could look at established independent accelerators and explore the organizational capabilities required for their successful operation and how performance gets impacted by different organizational approaches, linking theories on organizational learning to the design of the accelerator organization and program (see Cohen et al., 2018). 


\section{DISCUSSION AND CONCLUSION}

The accelerator has become a phenomenon of importance for management. The body of research around accelerators is relevant and timely, and its insights are having an impact on managerial practice. Despite the increasing use of the label, the accelerator has so far been poorly conceptualized due to the disproportionate focus on the empirical indicators such as the program package, and the context specificity and idiosyncrasy in the implications of existing research. This has arguably limited the coherence, cumulativeness and transferability of results drawn from this research. Responding to this challenge, this paper presented a systematic examination of existing research on the accelerator and suggested several contributions for both theory and practice.

We categorized and summarized the literature, thereby making it more accessible for academics and practitioners alike. Rather than focusing on the variants of the term and the different models based on their (diverse) services and other empirical indicators which extant literature has looked at (Pauwels et al., 2017; Malek et al., 2014), we classified the literature into four research orientations based on the theoretical contexts in which the term and variants are used: organizational learning and adaptation, entrepreneurial finance, entrepreneurial ecosystems, and corporate innovation and entrepreneurship. As part of the stream identification, we have explored the main roles that were attributed to the accelerator, the concepts that the accelerator is compared against and the key theories and literatures that were built on. The resulting summary revealed the foci and underlying assumptions within each stream and formed the basis of our synthesis.

Our synthesis expanded the current narrow conceptualization of the accelerator beyond its program package to include structure, function and purpose, thereby broadened our understanding of the accelerator and uncovering the (often implicit) similarities and differences in the use of the concept. We found that the accelerator concept across extant research showed 
similarities regarding its program package and structure and differences regarding its function and purpose. With regards to the latter, we argued that the identified research orientations regard the accelerator's function as either open-system or closed-system intermediation and its main purpose to revolve around either venture or system acceleration.

This review contributes to a novel and holistic framework for the study of accelerators (see Figure 1). The framework serves as a basis for investigating both the organizational and network-level processes and effects of accelerators and for capturing the multiple dimensions of intermediation. The resulting integrative typology demonstrated that there are four idealtypical views on the accelerator which we have named based on the transferability of findings to (1) organizational sponsors, (2) financial intermediaries, (3) ecosystem intermediaries and (4) start-up engagement vehicles. Hence, the typology regulates the applicability of studies' findings in different theoretical and empirical contexts.

Overall, we advance our understanding of the accelerator concept. Organizational scholars have called for research on "organizational forms not yet understood" (Greenwood \& Miller, 2010: 81) and explanations of specific mid-range forms (Greenwood, Hinings, \& Whetten, 2014; Miller, Greenwood, \& Prakash, 2009), rather than the more abstract organizational forms (e.g., the multidivisional structure or M-form) that have been subject of study in a time characterized by less organizational diversity (Greenwood \& Miller, 2010). This study focused on the accelerator as a multi-faceted and distinct organizational form and provided a common vocabulary for a scholarly community that can guide theoretical propositions and frameworks, and the selection of empirical units for investigation (Goertz, 2006).

Future research that bridges the divergent perspectives of the research orientations and more strongly connects research on accelerators to established theories could further contribute to our understanding of the accelerator and to the development of these theories. As most 
accelerators combine both open-system and closed-system intermediation as well as both venture and system acceleration, we call for studies on the tensions and coping mechanisms of such hybrid-system intermediaries and the entrainment challenges and practices of combining both types of acceleration. Furthermore, we suggest that research on the phenomenon of the accelerator could draw from and contribute to the established theories of entrepreneurial cognition, institutional theory, governance theory and organization design theory.

This study has several limitations. Due to the scope and scale of the literature covered in this paper, it has not been possible to do full justice to the subtleties and detailed findings of each research orientation. As such, we have focused on the features of the accelerator while not on how these organizational features could be executed best. A further limitation is that this review has focused on the concept of the accelerator from an organizational perspective. In developing our analysis of the organizational features of the accelerator and boundaries of the concept, we are aware that multiple levels of analysis come into play. Although we have alluded to systemlevel or individual-level analysis, we do not explore the theory and practice of the accelerator at a macro-level or micro-level. We believe further research and analytic work through these perspectives may be fruitful. However, as outlined in the introduction, the purpose of this review was to shed clarity around the organizational form of the accelerator and the different literature streams that ensue around it. 


\section{REFERENCES}

Ács, Z. J., Autio, E., \& Szerb, L. (2014). National systems of entrepreneurship: Measurement issues and policy implications. Research Policy, 43(3), 476-494.

Adner, R., \& Kapoor, R. (2010). Value creation in innovation ecosystems: How the structure of technological interdependence affects firm performance in new technology generations. Strategic management journal, 31(3), 306-333.

Aerts, K., Matthyssens, P., \& Vandenbempt, K. (2007). Critical role and screening practices of European business incubators. Technovation, 27(5), 254-267.

Amezcua, A. S., Grimes, M. G., Bradley, S. W., \& Wiklund, J. (2013). Organizational sponsorship and founding environments: a contingency view on the survival of business-incubated firms, 19942007. Academy of Management Journal, 56(6), 1628-1654.

Ancona, D. G., Goodman, P. S., Lawrence, B. S., \& Tushman, M. L. (2001). Time: A new research lens. Academy of management Review, 26(4), 645-663.

Ancona, D. G., Okhuysen, G. A., \& Perlow, L. A. (2001). Taking time to integrate temporal research. Academy of Management Review, 26(4), 512-529.

Ansari, S., Garud, R., \& Kumaraswamy, A. (2016). The disruptor's dilemma: TiVo and the US television ecosystem. Strategic Management Journal, 37(9), 1829-1853.

Armanios, D. E., Eesley, C. E., Li, J., \& Eisenhardt, K. M. (2017). How entrepreneurs leverage institutional intermediaries in emerging economies to acquire public resources. Strategic Management Journal, 38(7), 1373-1390.

Battistella, C., De Toni, A. F., \& Pessot, E. (2017). Open accelerators for start-ups success: a case study. European Journal of Innovation Management, 20(1), 80-111.

Barnett-Page, E., \& Thomas, J. (2009). Methods for the synthesis of qualitative research: a critical review. BMC medical research methodology, 9(1), 59.

Bernthal, B. (2016). Investment Accelerators. Stanford Journal of Law, Business, \& Finance. 21(2), 139-191.

Bernthal, B., (2017) Who Needs Contracts? Generalized Exchange within Investment Accelerators, 100 Marquette Law Review, Forthcoming: 2017.

Bernstein, S., Giroud, X., \& Townsend, R. R. (2016). The impact of venture capital monitoring. The Journal of Finance, 71(4), 1591-1622.

Bessant, J., \& Rush, H. (1995). Building bridges for innovation: the role of consultants in technology transfer. Research policy, 24(1), 97-114.

Bliemel, M. J., \& Flores, R. G. (2015). Defining and Differentiating Accelerators: Insights from the Australian Context. Academy of Management Proceedings.

Bluedorn, A. C., \& Denhardt, R. B. (1988). Time and organizations. Journal of management, 14(2), 299-320.

Boyatzis, R. E. (1998). Transforming qualitative information: Thematic analysis and code development. Sage.

Burgelman, R.A. 1983. A process model of internal corporate venturing in the diversified major firm.

Administrative Science Quarterly, 28(2), 223-244.

Burgelman, R.A. 1984. Designs for corporate entrepreneurship in established firms. California

Management Review, 26(3), 154-166.

Brown, S. L., \& Eisenhardt, K. M. (1997). The art of continuous change: Linking complexity theory and time-paced evolution in relentlessly shifting organizations. Administrative science quarterly, 1-34.

Bruton, G., Khavul, S., Siegel, D., \& Wright, M. (2015). New financial alternatives in seeding entrepreneurship: Microfinance, crowdfunding, and peer-to-peer innovations. Entrepreneurship Theory and Practice, 39(1), 9-26.

Bryan, K. A., Tilcsik, A., \& Zhu, B. (2017). Which Entrepreneurs Are Coachable and Why?. American Economic Review, 107(5), 312-16.

Carroll, G. R. (1984). Organizational ecology. Annual review of Sociology, 10(1), 71-93.

Chakravarthy, B. S. (1982). Adaptation: A promising metaphor for strategic management. Academy of management review, 7(1), 35-44. 
Chartered Association of Business Schools (CABS). (2018). Academic Journal Guide. Retrieved from https://charteredabs.org/academic-journal-guide-2018-view/

Chesbrough, H. W. (2003). Open innovation: The new imperative for creating and profiting from technology. Boston: Harvard Business School Press.

Chesbrough, H., \& Rosenbloom, R. S. (2002). The role of the business model in capturing value from innovation: evidence from Xerox Corporation's technology spin-off companies. Industrial and corporate change, 11(3), 529-555.

Clayton, P., Feldman, M., \& Lowe, N. (2018). Behind the scenes: Intermediary organizations that facilitate science commercialization through entrepreneurship. Academy of Management Perspectives, 32(1), 104-124.

Cohen, S. (2013). What do accelerators do? Insights from incubators and angels. innovations, 8(3-4), 19-25

Cohen, S., \& Hochberg, Y. V. (2014). Accelerating startups: The seed accelerator phenomenon. Available at SSRN: https://papers.ssrn.com/sol3/papers.cfm?abstract_id=2418000

Cohen, S. L., Bingham, C. B., \& Hallen, B. L. (2018). The Role of Accelerator Designs in Mitigating Bounded Rationality in New Ventures. Administrative Science Quarterly.

Connelly, B. L., Certo, S. T., Ireland, R. D., \& Reutzel, C. R. (2011). Signaling theory: A review and assessment. Journal of management, 37(1), 39-67.

Cooke, P., Uranga, M. G., \& Etxebarria, G. (1997). Regional innovation systems: Institutional and organisational dimensions. Research policy, 26(4-5), 475-491.

Denyer, D., Tranfield, D., \& Van Aken, J. E. (2008). Developing design propositions through research synthesis. Organization studies, 29(3), 393-413.

Dhanaraj, C., \& Parkhe, A. (2006). Orchestrating innovation networks. Academy of management review, 31(3), 659-669.

Doty, D. H., \& Glick, W. H. (1994). Typologies as a unique form of theory building: Toward improved understanding and modeling. Academy of management review, 19(2), 230-251.

Drori, I., \& Wright, M. (2018). Accelerators: characteristics, trends and the new entrepreneurial ecosystem. In: Wright, M., Drori, I. (eds.): Accelerators: Successful Venture Creation and Growth, Edward Elgar Press.

Drover, W., Busenitz, L., Matusik, S., Townsend, D., Anglin, A., \& Dushnitsky, G. (2017). A review and road map of entrepreneurial equity financing research: venture capital, corporate venture capital, angel investment, crowdfunding, and accelerators. Journal of Management, 43(6), 1820-1853.

Dutt, N., Hawn, O., Vidal, E., Chatterji, A., McGahan, A., \& Mitchell, W. (2016). How open system intermediaries address institutional failures: The case of business incubators in emergingmarket countries. Academy of Management Journal, 59(3), 818-840.

Fehder, D. C., \& Hochberg, Y. V. (2014). Accelerators and the regional supply of venture capital investment. Available at SSRN. (last consulted 01/02/2017)

Eberhart, R. N., \& Eesley, C. E. (2018). The Dark Side of Institutional Intermediaries: Junior Stock Exchanges and Entrepreneurship. Strategic Management Journal, Forthcoming: 2017.

Edler, J., \& Yeow, J. (2016). Connecting demand and supply: The role of intermediation in public procurement of innovation. Research Policy, 45(2), 414-426.

Eesley, C., Y. Wang. (2017). Social Influence in Entrepreneurial Career Choice: A Randomized Field Experiment on the Social Influence of Entrepreneurial Mentorship. Research Policy, Vol. 46(3): pp. 636-650.

Ewens, M., Nanda, R., \& Rhodes-Kropf, M. (2018). Cost of experimentation and the evolution of venture capital. Journal of Financial Economics, 128(3), 422-442.

Fiol, C. M., \& Lyles, M. A. (1985). Organizational learning. Academy of management review, 10(4), 803-813.

Gabrielsson, J., Politis, D., Persson, K. M., \& Kronholm, J. (2018). Promoting water-related innovation through networked acceleration: Insights from the Water Innovation Accelerator. Journal of Cleaner Production, 171, S130-S139.

Becker, B., \& Gassmann, O. (2006). Gaining leverage effects from knowledge modes within corporate incubators. $R \& d$ Management, 36(1), 1-16. 
Glaser, B.G \& Strauss, A.L. (1967) The Discovery of Grounded Theory: Strategies for Qualitative Research, Chicago: Aldine Publishing Company.

Giudici, A., Reinmoeller, P., \& Ravasi, D. (2018). Open-system orchestration as a relational source of sensing capabilities: evidence from a venture association. Academy of Management Journal, 61(4), 1369-1402.

Guillen, M. F. (2000). Business groups in emerging economies: A resource-based view. academy of Management Journal, 43(3), 362-380.

Gonzalez-Uribe, J., \& Leatherbee, M. (2017). The Effects of Business Accelerators on Venture Performance: Evidence from Start-Up Chile. Review of Financial Studies, hhx103, https://doi.org/10.1093/rfs/hhx103

Gompers, P., \& Lerner, J. (2000). Money chasing deals? The impact of fund inflows on private equity valuation. Journal of financial economics, 55(2), 281-325.

Gompers, P. A., \& Lerner, J. (2004). The venture capital cycle. MIT press.

Goswami K, Mitchell JR, Bhagavatula S (2018). Accelerator expertise: Understanding the intermediary role of accelerators in the development of the Bangalore entrepreneurial ecosystem. Strategic Entrepreneurship Journal.1-34. https://doi.org/10.1002/sej.1281.

Greenwood, R., \& Miller, D. (2010). Tackling design anew: Getting back to the heart of organizational theory. Academy of Management Perspectives, 24(4), 78-88.

Greenwood, R., Hinings, C. R., \& Whetten, D. (2014). Rethinking institutions and organizations. Journal of Management Studies, 51(7), 1206-1220.

Grégoire, D. A., Corbett, A. C., \& McMullen, J. S. (2011). The cognitive perspective in entrepreneurship: An agenda for future research. Journal of Management Studies, 48(6), 1443-1477.

Goertz, G. (2006). Social science concepts: A user's guide. Princeton University Press.

Grimaldi, R., \& Grandi, A. (2005). Business incubators and new venture creation: an assessment of incubating models. Technovation, 25(2), 111-121.

Grimes, M. (2017). The Pivot: How Founders Respond to Feedback Through Idea and Identity Work. Academy of Management Journal, Published online ahead of print. DOI:10.5465/amj.2015.0823.

Hallen, B. L., Bingham, C. B., \& Cohen, S. (2014). Do accelerators accelerate? A study of venture accelerators as a path to success? In: Academy of management proceedings.

Hathaway, I. 2016. What startup accelerators really do. Harvard Business Review, March 1, 2016. Available at: http://tinyurl.com/jtmpq86.

Hart, Oliver. "Corporate governance: some theory and implications." The economic journal 105, no. 430 (1995): 678-689.

Hoon, C. (2013). Meta-Synthesis of Qualitative Case Studies An Approach to Theory Building. Organizational Research Methods, 16(4), 522-556.

Howells, J. (2006). Intermediation and the role of intermediaries in innovation. Research policy, 35(5), 715-728.

Hsu, G., \& Hannan, M. T. (2005). Identities, genres, and organizational forms. Organization Science, 16(5), 474-490.

Jackson, P., \& Richter, N. (2017). Situational logic: An analysis of open innovation using corporate accelerators. International Journal of Innovation Management, 21(07), 1750062.

Jensen, L. A., \& Allen, M. N. (1996). Meta-synthesis of qualitative findings. Qualitative health research, 6(4), 553-560.

Kanbach, D. K., \& Stubner, S. (2016). Corporate Accelerators As Recent Form Of Startup Engagement: The What, The Why, And The How. Journal of Applied Business Research (JABR), 32(6), 1761-1776.

Kazanjian, R. K. (1988). Relation of dominant problems to stages of growth in technology-based new ventures. Academy of management journal, 31(2), 257-279.

Kepes, S., Banks, G. C., McDaniel, M., \& Whetzel, D. L. (2012). Publication bias in the organizational sciences. Organizational Research Methods, 15(4), 624-662.

Kim, J.-H. and L. Wagman (2014). "Portfolio size and information disclosure: An analysis of startup accelerators." Journal of Corporate Finance 29: 520-534. 
Kohler, T. (2016). Corporate accelerators: Building bridges between corporations and startups. Business Horizons, 59(3), 347-357.

Klerkx, L., \& Leeuwis, C. (2008). Balancing multiple interests: Embedding innovation intermediation in the agricultural knowledge infrastructure. Technovation, 28(6), 364-378.

Kreusel, N., Roth, N., \& Brem, A. (2018). European business venturing in times of digitisation-an analysis of for-profit business incubators in a triple helix context. International Journal of Technology Management, 76(1-2), 104-136.

Leatherbee, M., \& Eesley, C. (2014). Boulevard of broken behaviors: Socio-psychological mechanisms of entrepreneurship policies.

Lifshitz-Assaf, H., Lebovitz, S., \& Zalmanson, L. (2018). The Importance of Breaking Instead of Compressing Time in Accelerated Innovation: A Study of Makeathons' New Product Development Process. Available at SSRN 3280219.

Malek, K., Maine, E., \& McCarthy, I. P. (2014). A typology of clean technology commercialization accelerators. Journal of Engineering and Technology Management, 32, 26-39.

Mahmoud-Jouini, S. B., Duvert, C., \& Esquirol, M. (2018). Key Factors in Building a Corporate Accelerator Capability: Developing an effective corporate accelerator requires close attention to the relationships between startups and the sponsoring company. Research-Technology Management, 61(4), 26-34.

Mair, J., Marti, I., \& Ventresca, M. J. (2012). Building inclusive markets in rural Bangladesh: How intermediaries work institutional voids. Academy of Management Journal, 55(4), 819-850.

McKelvey, B. (1982). Organizational systematics--taxonomy, evolution, classification. Univ of California Press.

Mian, S., Lamine, W., \& Fayolle, A. (2016). Technology business incubation: An overview of the state of knowledge. Technovation, 50, 1-12.

Miles, M. P., \& Covin, J. G. (2002). Exploring the practice of corporate venturing: Some common forms and their organizational implications. Entrepreneurship theory and practice, 26(3), 2140.

Miller, P., \& Bound, K. (2011). The Startup Factories: The rise of accelerator programmes to support new technology ventures. Nesta.

Miller, D., Greenwood, R., \& Prakash, R. (2009). What happened to organization theory?. Journal of Management Inquiry, 18(4), 273-279.

Mitchell, R. K., Busenitz, L., Lant, T., McDougall, P. P., Morse, E. A., \& Smith, J. B. (2002). Toward a theory of entrepreneurial cognition: Rethinking the people side of entrepreneurship research. Entrepreneurship theory and practice, 27(2), 93-104.

Moore, J. F. (1996). The death of competition: leadership and strategy in the age of business ecosystems (p. 297). New York: HarperBusiness.

Nambisan, S., \& Baron, R. A. (2013). Entrepreneurship in innovation ecosystems: Entrepreneurs' selfregulatory processes and their implications for new venture success. Entrepreneurship Theory and Practice, 37(5), 1071-1097.

Nambisan, S., \& Sawhney, M. (2011). Orchestration processes in network-centric innovation: Evidence from the field. Academy of management perspectives, 25(3), 40-57.

Narayanan, V. K., Yang, Y., \& Zahra, S. A. (2009). Corporate venturing and value creation: A review and proposed framework. Research policy, 38(1), 58-76.

North, D.C., 1990. Institutions, Institutional Change, and Economic Performance. Cambridge University Press, New York.

North, D. C. (2003). The new institutional economics and third world development. In The new institutional economics and third world development (pp. 31-40). Routledge.

O'Mahony, S., \& Bechky, B. A. (2008). Boundary organizations: Enabling collaboration among unexpected allies. Administrative science quarterly, 53(3), 422-459.

O'Mahony, S., \& Karp, R. (2017). From proprietary to collective governance: How platform participant strategies adapt. Working Paper.

Pache, A. C., \& Santos, F. (2013). Inside the hybrid organization: Selective coupling as a response to competing institutional logics. Academy of Management Journal, 56(4), 972-1001. 
Pahnke, E. C., Katila, R., \& Eisenhardt, K. M. (2015). Who takes you to the dance? How partners' institutional logics influence innovation in young firms. Administrative Science Quarterly, 60(4), 596-633.

Pandey, S., Lall, S., Pandey, S. K., \& Ahlawat, S. (2017). The appeal of social accelerators: what do social entrepreneurs value?. Journal of Social Entrepreneurship, 8(1), 88-109.

Pauwels, C., Clarysse, B., Wright, M., \& Van Hove, J. (2016). Understanding a new generation incubation model: The accelerator. Technovation, 50, 13-24.

Pérez-Nordtvedt, L., Payne, G. T., Short, J. C., \& Kedia, B. L. (2008). An entrainment-based model of temporal organizational fit, misfit, and performance. Organization Science, 19(5), 785-801.

Phan, P. H., Siegel, D. S., \& Wright, M. (2005). Science parks and incubators: observations, synthesis and future research. Journal of business venturing, 20(2), 165-182.

Phan, P. H., Wright, M., Ucbasaran, D., \& Tan, W. L. (2009). Corporate entrepreneurship: Current research and future directions. Journal of business Venturing, 24(3), 197-205.

Pilbeam, K. (2005). Financial intermediation and financial markets. In Finance and financial markets (pp. 22-38). Palgrave, London.

Plummer, L. A., Allison, T. H., \& Connelly, B. L. (2016). Better together? Signaling interactions in new venture pursuit of initial external capital. Academy of Management Journal, 59(5), 15851604.

Pólos, L., Hannan, M. T., \& Carroll, G. R. (2002). Foundations of a theory of social forms. Industrial and corporate change, 11(1), 85-115.

Prexl, K. M., Hubert, M., Beck, S., Heiden, C., \& Prügl, R. (2018). Identifying and analysing the drivers of heterogeneity among ecosystem builder accelerators. $R \& d$ Management.

Richter, N., Jackson, P., \& Schildhauer, T. (2018). Radical Innovation Using Corporate Accelerators: A Program Approach. In Entrepreneurial Innovation and Leadership (pp. 99-108). Palgrave Pivot, Cham.

Romanelli, E. (1991). The evolution of new organizational forms. Annual review of sociology, 17(1), 79-103.

Rousseau, D. M., Manning, J., \& Denyer, D. (2008). Evidence in management and organizational science: Assembling the field's full weight of scientific knowledge through syntheses. The academy of management annals, 2(1), 475-515.

Rosa, H. (2013). Social acceleration: A new theory of modernity. Columbia University Press.

Sanders, W. G., \& Boivie, S. (2004). Sorting things out: Valuation of new firms in uncertain markets. Strategic Management Journal, 25(2), 167-186.

Sapienza, H. J. (1992). When do venture capitalists add value?. Journal of Business Venturing, 7(1), 9-27.

Sanchez, R., \& Mahoney, J. T. (1996). Modularity, flexibility, and knowledge management in product and organization design. Strategic management journal, 17(S2), 63-76.

Scillitoe, J. L., \& Chakrabarti, A. K. (2010). The role of incubator interactions in assisting new ventures. Technovation, 30(3), 155-167.

Scott, W. R. (1995). Institutions and organizations. Foundations for organizational science. London: A Sage Publication Series.

Shankar, R. K., \& Shepherd, D. A. (2018). Accelerating strategic fit or venture emergence: Different paths adopted by corporate accelerators. Journal of Business Venturing.

Short, J. C., Payne, G. T., \& Ketchen Jr, D. J. (2008). Research on organizational configurations: Past accomplishments and future challenges. Journal of management, 34(6), 1053-1079.

Sivonen, P., Borella, P., Thomas, L. D., \& Sharapov, D. (2015). How an Accelerator can Catalyse your Ecosystem. European Business Review.

Souitaris, V., Zerbinati, S., \& Liu, G. (2012). Which iron cage? Endo-and exoisomorphism in corporate venture capital programs. Academy of Management Journal, 55(2), 477-505.

Spence, M. 1973. Job market signaling. Quarterly Journal of Economics, 87: 355-374

Stayton, J., \& Mangematin, V. Seed accelerators and the speed of new venture creation. The Journal of Technology Transfer, 1-25.

Stoker, G. (1998). Governance as theory: five propositions. International social science journal, 50(155), 17-28. 
Thomas, L. D., Autio, E., \& Gann, D. M. (2014). Architectural leverage: putting platforms in context. The Academy of Management Perspectives, 28(2), 198-219.

Thomas, J., \& Harden, A. (2008). Methods for the thematic synthesis of qualitative research in systematic reviews. BMC medical research methodology, 8(1), 45.

Tranfield, D., Denyer, D., \& Smart, P. (2003). Towards a methodology for developing evidenceinformed management knowledge by means of systematic review. British journal of management, 14(3), 207-222.

Weiblen, T., \& Chesbrough, H. W. (2015). Engaging with startups to enhance corporate innovation. California Management Review, 57(2), 66-90.

Wooten, M., \& Hoffman, A. J. (2008). Organizational fields: Past, present and future. The Sage handbook of organizational institutionalism, 1, 131-147.

Yang, S., Kher, R., \& Lyons, T. S. (2018). Where Do Accelerators Fit in the Venture Creation Pipeline? Different Values Brought by Different Types of Accelerators. Entrepreneurship Research Journal, 8(4).

Yin, R. K. (2011). Applications of case study research. Sage.

Yin, B., \& Luo, J. (2018). How Do Accelerators Select Startups? Shifting Decision Criteria Across Stages. IEEE Transactions on Engineering Management.

Younger, S., \& Fisher, G. (2018). The exemplar enigma: New venture image formation in an emergent organizational category. Journal of Business Venturing.

$\mathrm{Yu}$, S. (2014). "The impact of accelerators on high-technology ventures." Available at SSRN 2503510.

Zietsma, C., Groenewegen, P., Logue, D. M., \& Hinings, C. R. (2017). Field or fields? Building the scaffolding for cumulation of research on institutional fields. Academy of Management Annals, 11(1), 391-450.

Zott, C., Amit, R., \& Massa, L. (2011). The business model: recent developments and future research. Journal of management, 37(4), 1019-1042. 
TABLE 1

\section{Overview of Included Studies in Review}

\begin{tabular}{lr}
\hline & $\begin{array}{r}\text { Nb. of } \\
\text { studies }\end{array}$ \\
\hline Jype & $\mathbf{4 1}$ \\
Manal publications & 20 \\
Academy of Management Journal (1), Academy of Management Perspectives & \\
(1), Administrative Science Quarterly (1), Journal of Management (1), Business & \\
Horizons (1), California Management Review (1), Journal of Engineering and & \\
Technology Management (1), Technology Innovation Management Review (1), & \\
Journal of Business Research (1), European Journal of Innovation & \\
Management (1), Innovations (1), Journal of Engineering and Technology & \\
Management (1), International Journal of Innovation Management (1), Journal & \\
of Applied Business Research (1), Creativity and Innovations Management (1), & \\
European Business Review (1), International Journal of Technology & \\
Management (1), IEEE Transaction on Engineering Management (1), & \\
Research-Technology Management (1), R\&D Management (1) & \\
Entrepreneurship & \\
Journal of Business Venturing (3), Technovation (2), The Journal of & \\
Technology Transfer (2), Entrepreneurship Theory and practice (2), Strategic & \\
Entrepreneurship Journal (2), European Business Venturing (1), Journal of & \\
Social Entrepreneurship (1), Entrepreneurship Research Journal (1) & \\
Business Finance & $\mathbf{2}$ \\
Journal of Corporate Finance (1), Journal of Private Equity (1), Review of & \\
Financial Studies (1), Journal of Financial Economics (1), Stanford Journal of & \\
Law, Business, and Finance (1), & \\
Other & \\
Journal of Cleaner Production (1), Marquette Law Review (1) & \\
Conference proceedings & \\
Think tank reports & \\
Unpublished / unsubmitted research & \\
\hline Total & \\
\hline
\end{tabular}


TABLE 2

Overview of Different Research Orientations on the Accelerator

\begin{tabular}{|c|c|c|c|c|}
\hline $\begin{array}{l}\text { Research } \\
\text { orientation }\end{array}$ & $\begin{array}{c}\text { Organizational learning } \\
\text { and adaptation }\end{array}$ & Entrepreneurial finance & Entrepreneurial ecosystems & $\begin{array}{c}\text { Corporate innovation and } \\
\text { entrepreneurship }\end{array}$ \\
\hline Roles & $\begin{array}{l}\text { Organizational sponsor, } \\
\text { new generation } \\
\text { incubation model, } \\
\text { supportive organizational } \\
\text { entity }\end{array}$ & $\begin{array}{l}\text { Financial intermediary, } \\
\text { small VC-fund, spray- } \\
\text { and-pray model }\end{array}$ & $\begin{array}{l}\text { Ecosystem intermediary, } \\
\text { physical space } \\
\text { intermediary, innovation } \\
\text { intermediary }\end{array}$ & $\begin{array}{l}\text { Corporate startup } \\
\text { engagement vehicle, } \\
\text { outside-in innovation } \\
\text { program }\end{array}$ \\
\hline Focal beneficiaries & - Portfolio companies & - Investors & $\begin{array}{l}\text { - Entrepreneurial } \\
\text { ecosystem }\end{array}$ & $\begin{array}{l}\text { - Corporate sponsor / } \\
\text { (eco)system }\end{array}$ \\
\hline $\begin{array}{l}\text { Key theories / } \\
\text { concepts }\end{array}$ & $\begin{array}{l}\text { Business models, } \\
\text { organizational learning }\end{array}$ & $\begin{array}{l}\text { Startup finance, } \\
\text { signaling, governance }\end{array}$ & $\begin{array}{l}\text { Entrepreneurial } \\
\text { ecosystems, innovation } \\
\text { systems }\end{array}$ & $\begin{array}{ll} & \text { Corporate } \\
\text { entrepreneurship, open } \\
\text { innovation, innovation / } \\
\text { business ecosystems }\end{array}$ \\
\hline Empirical setting & - All accelerators & - Investment accelerators & - All accelerators & - Corporate accelerators \\
\hline Main Works & $\begin{array}{l}\text { Cohen et al., 2018; } \\
\text { Younger \& Fisher, 2018; } \\
\text { Stayton \& Mangematin, } \\
2017\end{array}$ & $\begin{array}{l}\text { Kim \& Wagman, 2012; } \\
\text { Ewens } \text { et al., 2016; } \\
\text { Drover } \text { et al., } 2017\end{array}$ & $\begin{array}{l}\text { Goswami et al., 2018; } \\
\text { Clayton et al., 2018; } \\
\text { Yang et al., } 2017\end{array}$ & $\begin{array}{l}\text { Shankar \& Shepherd, } \\
\text { 2018; Chesbrough \& } \\
\text { Weibin, 2015; Kohler, } \\
2016\end{array}$ \\
\hline
\end{tabular}


FIGURE 1

Accelerator Conceptualizations from Different Research Orientations

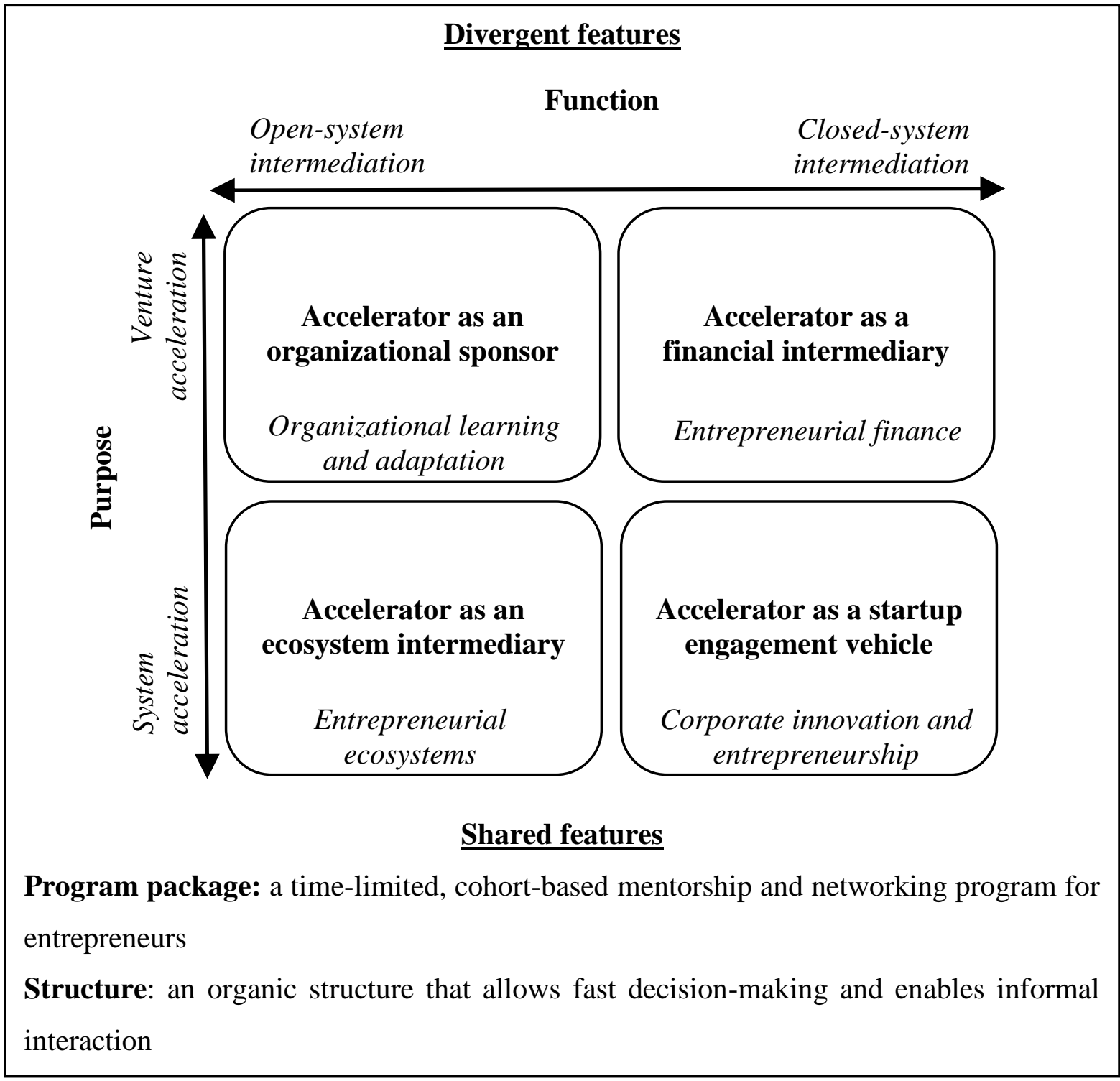

